\title{
Application Of Tourist Route Map Based On Modification Bidirectional A* Algorithm
}

\author{
Panji Winata*1, Wijanarto ${ }^{2}$ \\ Faculty of Computer Science, Universitas Dian Nuswantoro Semarang \\ e-mail : panjiwinata01@gmail.com*1,wijanarto.udinus@gmail.com ${ }^{2}$ \\ *Corresponding author
}

\begin{abstract}
Tourism is an activity that has become a trend of human needs. The development of technology in the current era is very helpful in providing such information to tourists, one of which is information about the route in the planning of tourism activities. Tourists will certainly choose the optimal route in their journey to make their tours more effective. In order to determine the fastest route, this paper will present a mobile-based application that will help tourists to quickly reach the destination. The Efficient Modified Bidirectional A* algorithm is chosen because it will provide an efficient route with shorter distance, which is a modification of the $A^{*}$ algorithm. The results of the case study of 5 trips from the starting point toward the goal resulted in a high level of efficiency ( 3 cases) and quite good ( 3 cases) with values, $77.5 \%$, $53 \%, 53.8 \%, 73 \%, 72.6 \%$. The above percentage is calculated by finding a proportional distance (d) of choice with the distance of all possible paths, then subtracting 1 by multiplying $d$ by $100 \%$. In the future work needed to add the parameters of the busy road route or not to be selected more optimal.
\end{abstract}

Keywords - GIS (Geographic Information System), Efficient Modified Bidirectional A* , Optimum route finding

\section{INTRODUCTION}

The field of Tourism is one of the areas of human life that requires information. Various information about the development of tourism, supporting facilities, attractions, visitors to information about the population around the object of tourism is an important thing to know tourists. The main focus is that tourists need information about the route to plan a trip from residence to the object of the destination[1].

Traffic congestion is both a problem and a challenge that modern cities face. For road users, a traffic jam can lead to an increase in travel time to a place. A network of damaged road infrastructure can be an obstacle for road users to be able to have good mobility. To solve these problems should be not only with the improvement of physical infrastructure and government policies, on the other hand, building a transportation management information system is indispensable[2].

GIS is a system consisting of hardware, software, data, brainwave, organizations and institutions used to collect, store, analyze, and disseminate information in relation to regions on the surface of the earth [3]. GIS is implemented with computer hardware and software that functions for data acquisition and verification, data compilation, data storage, changes and 
updating of data, management and data exchange, data manipulation, data calling and presentation and data analysis[4].

Answering the problems gained by residents in big cities and tourists where difficulty in determining the fastest alternative path to get to a place then GIS (Geographic Information System) can be a solution[5]. The use of Geographic Information Systems replaces the role of analogue maps that are inaccurate, less appropriate to geographical conditions and difficulty in the process of data changes [6].

This research uses heuristic search method with Efficient Modified Bidirectional A * algorithm. Efficient Modified Bidirectional $A *$ becomes the preferred algorithm because it has advantages compared to $A *$ even Bidirectional $A *$, as it ensures optimal route in search as well as faster travel time due to bidirectional optimization by minimizing the cost of forward and backward search route combined with function heuristics. Moreover, it has been proved by a case of searching for routes on a road network in Seoul, the algorithm is capable of generating a cost route of only half a time from the $A *[7]$.

\section{RESEARCH METHOD}

In solving the problem, applied a method and algorithm that appropriate with research purpose. The method is a series of actions performed to achieve the desired research results. In each stage of the method determines the process at a later stage which means it shows the dependence between stages. The proposed method can be described as follows:

Data collection of tourism object in Semarang City in Semarang City Tourism Office

The data of a tourist object including its coordinates is included in the database

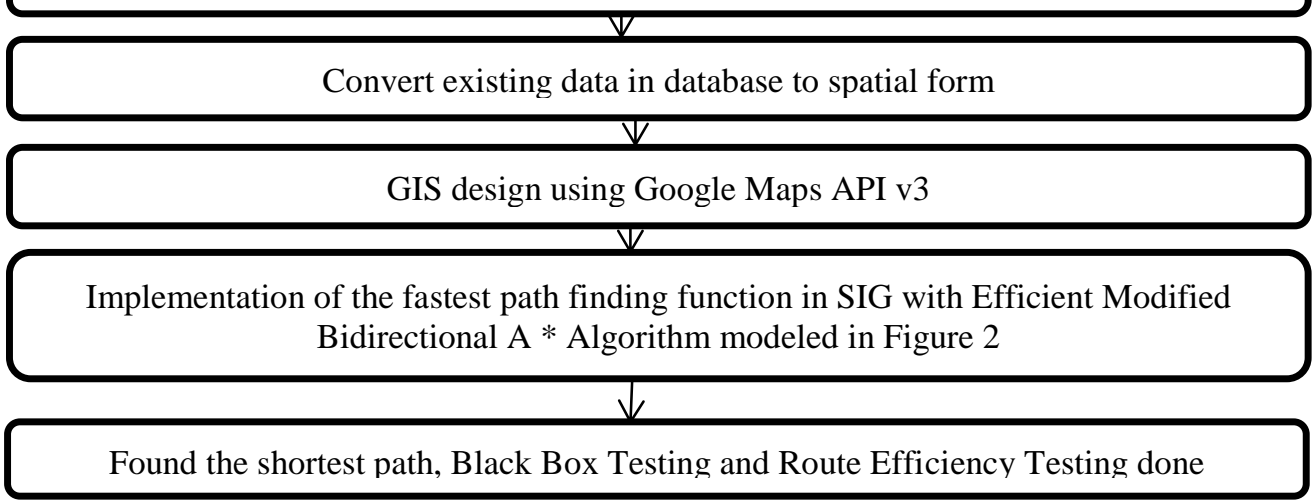

Figure 1 Overview of the Proposed Method

In the early stages of the study, observations were made to several tourist attractions in Semarang City to determine the geographical condition of the tourist attractions. Followed by a visit to the Tourism Office of Semarang City to communicate with regard to the condition of tourism in the city of Semarang. Not only communications, researchers also apply for valid data on tourist attractions. The database is created to accommodate all data about the sights and their descriptions including the coordinates of the location and type of tours. Performed data conversion on the database to spatial form to be input on GIS designed. By using Google API, SIG is designed using PHP so that GIS runs on a web basis. Search function with the heuristic algorithm of Efficient Modified Bidirectional A* is implemented in GIS designed to search the shortest path to the targeted tourist object. Here is a model representation of the steps of Efficient Modified Bidirectional A* : 


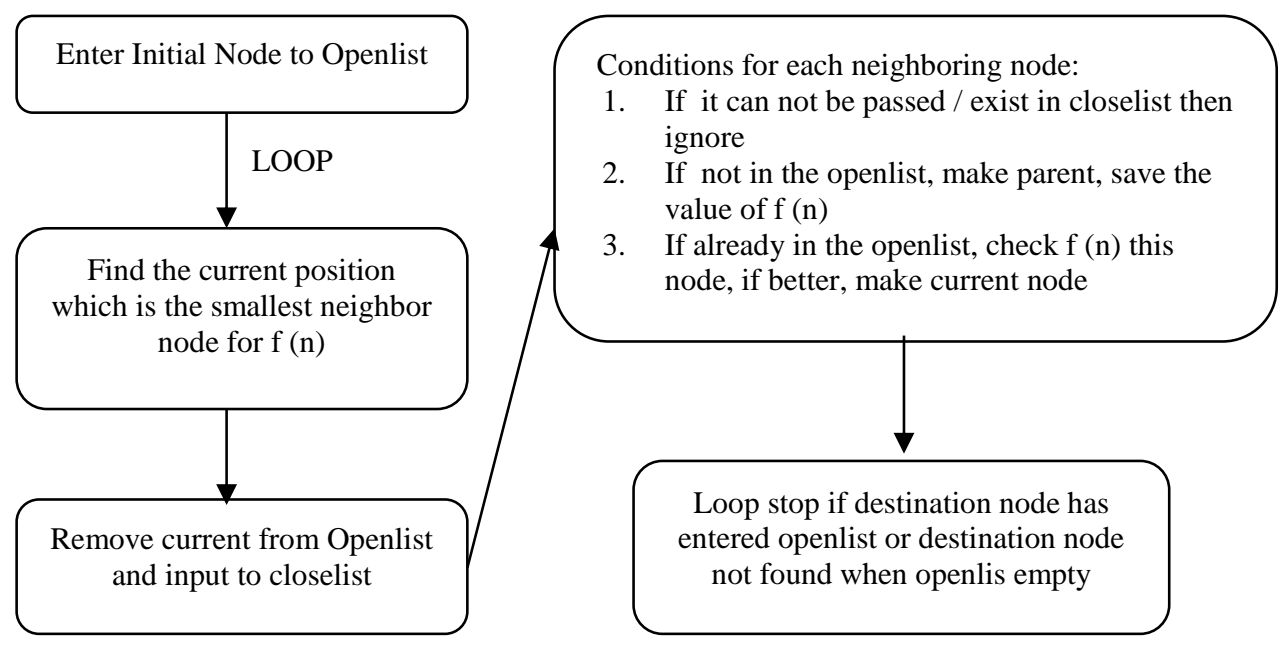

Figure 2 Model of Efficient Modified Bidirectional A Algorithm*

Before creating an application, researchers designed an architecture that provides a brief visualization of how the application will run coherently and systematically from input to output. Referring to figure 3 , the system architecture created by the researcher is as follows:

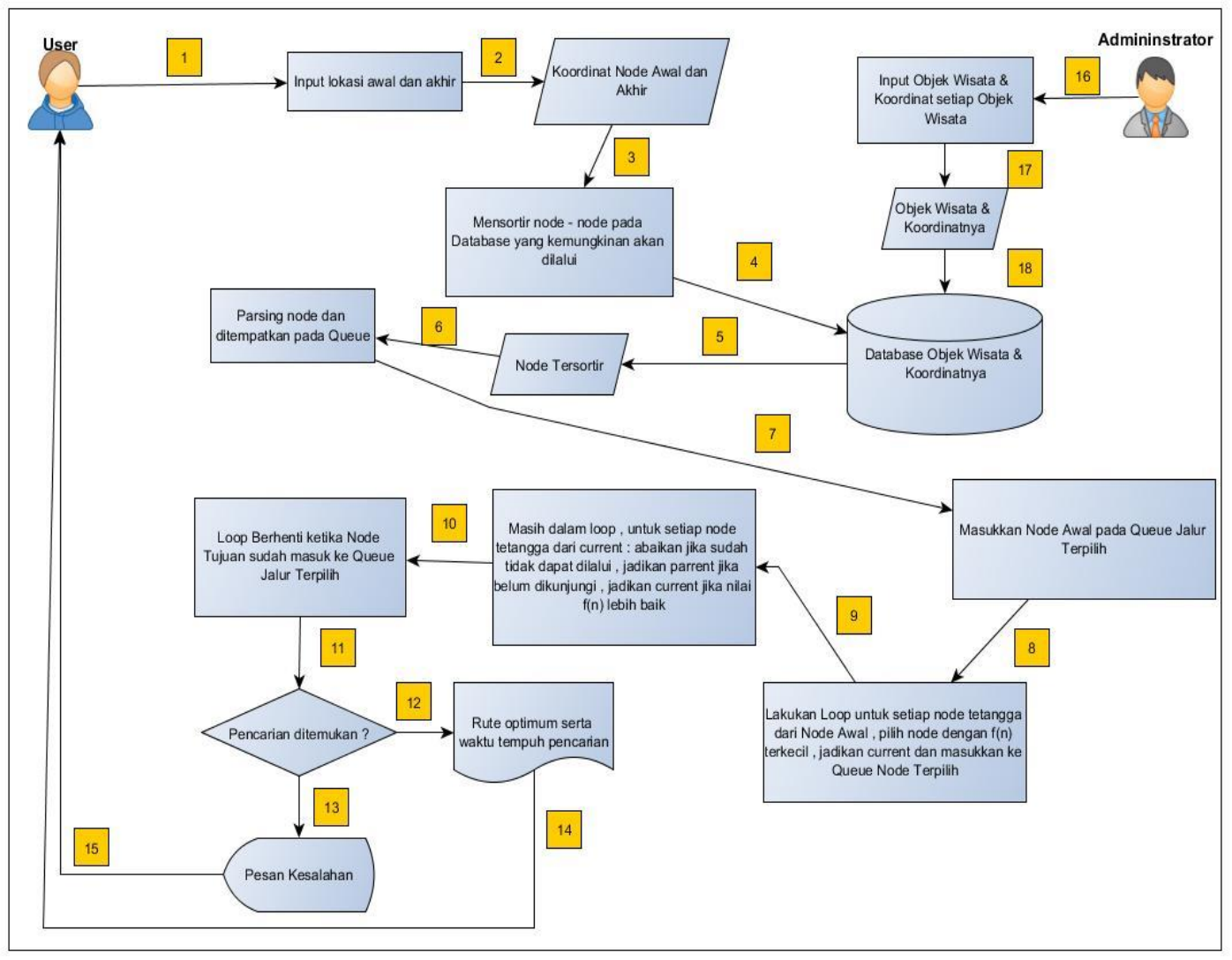

Figure 3 System Architecture

The following is the description of the numbers on the system architecture:

1. User opens the main page

2. Get user input as data 
3. Set up matching with stored nodes

4. Sort against existing nodes in the database

5. Get node sort results as data

6. Preparing to parse of nodes

7. Preparing the search for the destination object with the Algorithm of Efficient Modified Bidirectional A *

8. Part of the search implementation process with EMBA *

9. Part of the search implementation process with EMBA *

10. Part of the search implementation process with EMBA *

11. Preparing feedback to users

12. Set up next steps if search is found

13. Set up next step if search is not found

14. Presents the shortest route and the value of the route efficiency to the user

15. Displays error messages against search errors that occur to the user

16. Admin login

17. Input the admin into data

18. Storing data in the database

\section{RESULTS AND DISCUSSION}

In conducting a series of research processes, researchers need materials to support the design so that the results and objectives of the application are achieved with appropriate and appropriate expectations. As for some of the necessary needs are hardware requirements, software requirements, data requirements, system specifications and systematic system work. The following is a specification of the hardware and software requirements used in this study:

Table 1 Specification Requirements of Software and Hardware

\begin{tabular}{|c|c|}
\hline Hardware Specifications & Software Specification \\
\hline Processor Intel Core i3-2310M 2.1 GHz & Windows 7 Ultimate 32-bit \\
\hline Ram 4 GB & Yed Graph Editor \\
\hline Harddisk 500GB & Sublime Text 3 \\
\hline Monitor LCD 14" & Google Chrome \\
\hline & Xampp \\
\hline & PHP \\
\hline
\end{tabular}

In a series of research processes including design, researchers make use case diagrams and activity diagrams as follows: The use case diagram referred to in FIG. 4 illustrates the role of the actor of the system including the actions actor can perform in the system which is represented in the form of a diagram. The actor in the Optimum Travel Route EMBA* application is the user. Here is a use case diagram of the Optimum Travel Route NBA * application: 


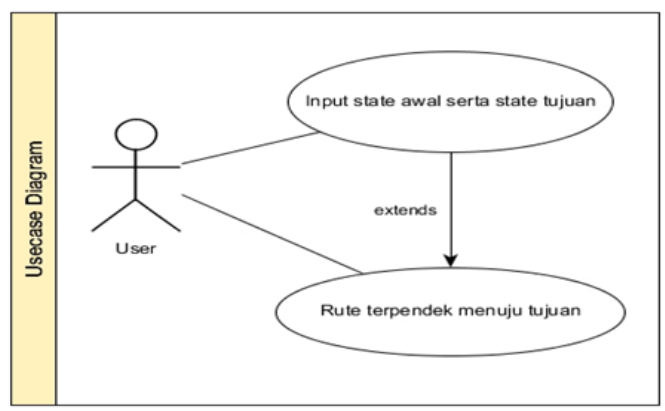

Figure 4 Use case Diagram

Below is a table describing use case diagram that has been designed, as follows:

Table 2 Explanation of Use case Diagram

\begin{tabular}{|c|l|}
\hline \multicolumn{1}{|c|}{ Process } & \multicolumn{1}{c|}{ Description } \\
\hline Initial input state as well as destination state & $\begin{array}{l}\text { Users make input to the system in the form of } \\
\text { initial state coordinates as well as the final state } \\
\text { which is done by selecting through the } \\
\text { dropdown menu on the application interface }\end{array}$ \\
\hline The shortest route to the destination & $\begin{array}{l}\text { Users get the output in the form of display the } \\
\text { optimum route to the final state of destination } \\
\text { after the coordinates of input in the process }\end{array}$ \\
\hline
\end{tabular}

Activity diagram referred to Figure 5 is used as the basis for modeling the performance flow of the process contained in the application of Optimum Travel Route EMBA * and the sequence of activities in a process, where the process is to find the optimum route and the efficiency of the route by implementing the Efficient Modified Bidirectional $A *$. In addition, the Activity diagram is also used as a reference to the implementation results of the design where the user and the system whether to run each activity according to permissions respectively. Here is the design activity diagram:

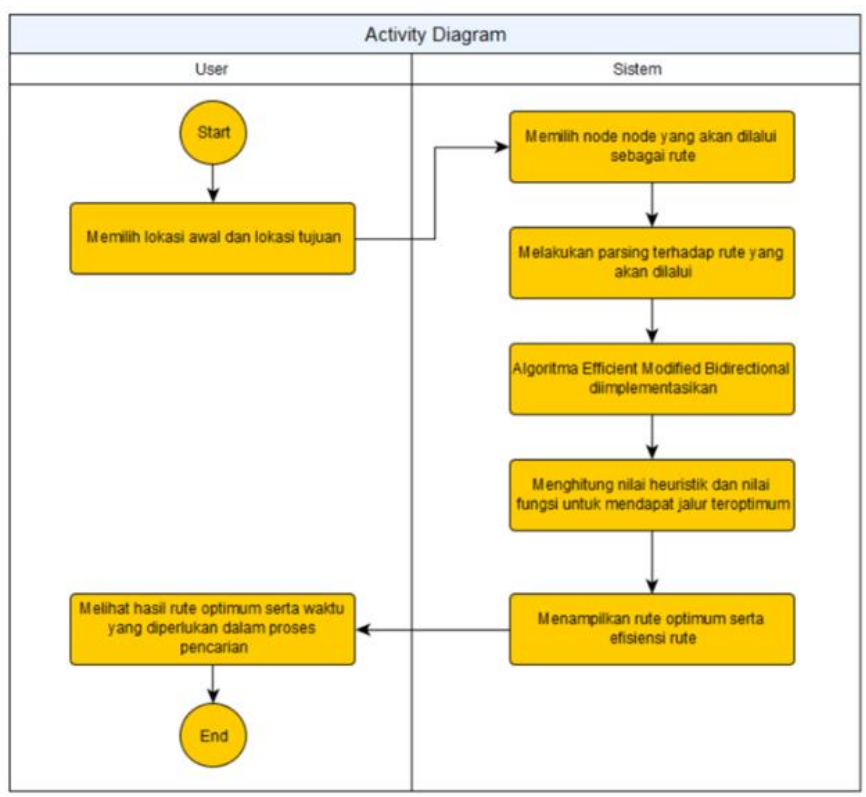

Figure 5 Activity Diagram 
After the implementation, the following is a view of the resulting application:

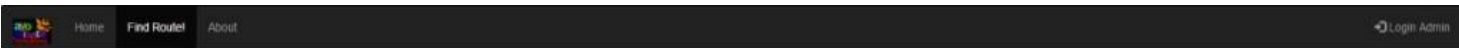

Cari Rute ke Objek Wisata

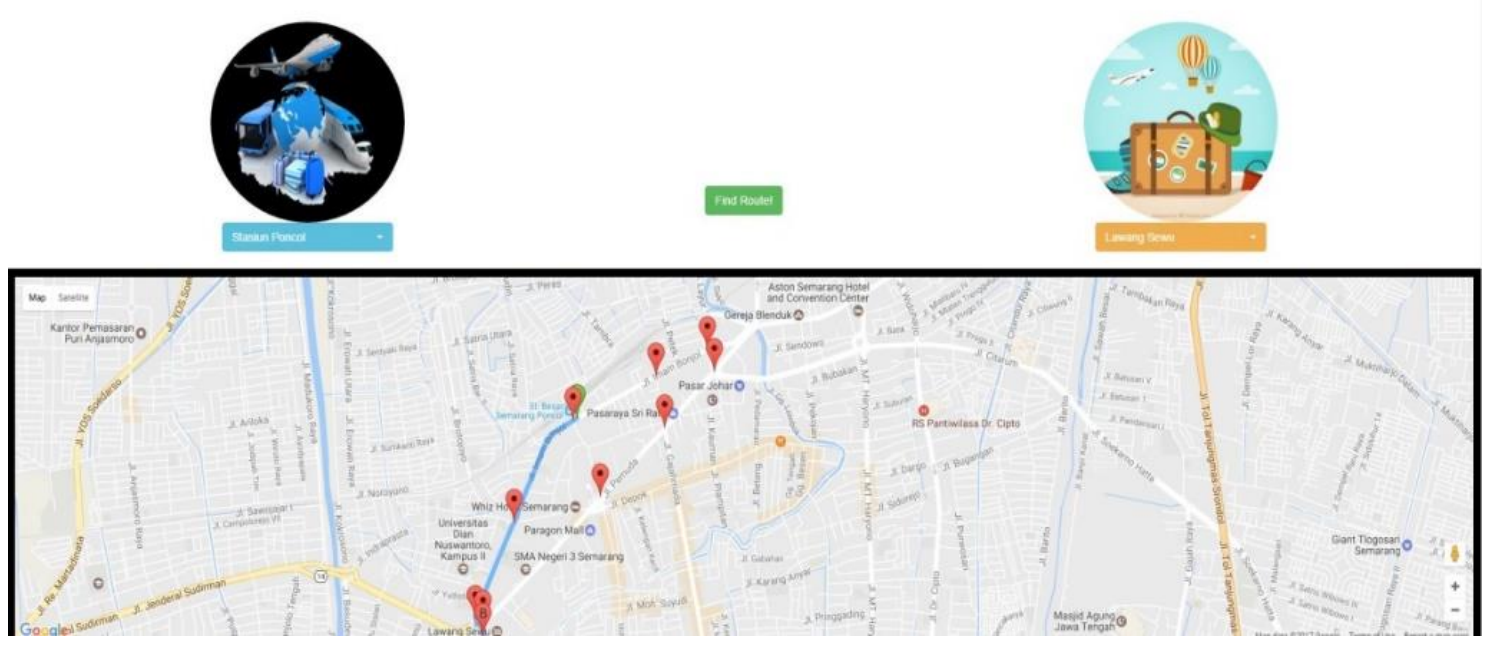

Figure 6 Display Shortest Path Result Search

By performing the shortest path search through the application, the comparison is performed with the manual shortest path counting results. If the result of the application is in accordance with the manual count and the result has the best efficiency among other lines, then the test is stopped. Testing the efficiency of this route based on the concept of mathematical comparison ratio, the ratio is a relationship between one number with another number. From the concept of ratio, found the formula as follows:

$$
\text { Test }=\frac{\text { Distance of Path selected }}{\text { Distance of all Skippable Paths }}
$$

From the equation, if a path chosen when calculated has the smallest result among others, then the path is the most efficient because it has the smallest ratio to the total distance of all the paths found. Percentage Efficiency can be calculated as follows:

$$
\text { Percentage }=1-\text { Test } \times 100 \%
$$

This Efficiency Test is conducted on the 5 case studies listed in table 3. Route efficiency testing is done as follows :

\begin{tabular}{|c|c|c|c|c|c|}
\hline No & Case & Node & Path & $\begin{array}{l}\text { Percentage of Route } \\
\text { Efficiency (\%) }\end{array}$ & Category \\
\hline 1 & $\begin{array}{l}\text { Stasiun } \\
\text { Poncol to } \\
\text { Lawang } \\
\text { Sewu }\end{array}$ & $\begin{array}{l}\text { A,B,C,D, } \\
E, F, G, H, I \\
, J, K, L\end{array}$ & A-D-K-C-B-J-L & $\begin{array}{l}\text { 1- } \\
(1,44 / 1,44+1,6+3,36) \\
* 100 \%=77,5 \%\end{array}$ & efficient \\
\hline 2 & $\begin{array}{l}\text { Bandara } \\
\text { Ahmad } \\
\text { Yani to }\end{array}$ & $\begin{array}{l}\text { A,B,C,D, } \\
E, F, G, H, I \\
\text { J,K,L,M, }\end{array}$ & $\begin{array}{l}\text { A-B-C-D-E-F- } \\
\text { G-H-I-J-K-L- } \\
\text { M-N-O-R }\end{array}$ & $\begin{array}{l}1-(3,8 / 3.8+4,3) * \\
100 \%=53 \%\end{array}$ & adequate \\
\hline
\end{tabular}

Table 3 Route Efficiency Testing 


\begin{tabular}{|c|c|c|c|c|c|}
\hline & $\begin{array}{l}\text { Taman } \\
\text { Maerokoco }\end{array}$ & $\begin{array}{l}N, O, P, Q, \\
R\end{array}$ & & & \\
\hline 3 & $\begin{array}{l}\text { Terminal } \\
\text { Sukun to } \\
\text { Hutan } \\
\text { Wisata } \\
\text { Tinjomoyo }\end{array}$ & $\begin{array}{l}A, B, C, D, \\
E, F, G, H, I \\
\text { J,K,L,M, } \\
N, O, P, Q\end{array}$ & $\begin{array}{l}\text { A-B-C-D-E-F- } \\
\text { G-P-H-I-J-Q }\end{array}$ & $\begin{array}{l}1-(7,1 / 7,1+8,3) * \\
100 \%=53,8 \%\end{array}$ & adequate \\
\hline 4 & $\begin{array}{l}\text { Terminal } \\
\text { Terboyo to } \\
\text { Masjid } \\
\text { Agung } \\
\text { Semarang }\end{array}$ & $\begin{array}{l}A, B, C, D \\
E, F, G, H, I\end{array}$ & A-B-C-D-G-J & $\begin{array}{l}\text { 1- } \\
(5,24 /(5,24+6,6+7,6)) \\
=73 \%\end{array}$ & efficient \\
\hline 5 & $\begin{array}{l}\text { Stasiun } \\
\text { Tawang to } \\
\text { Mall } \\
\text { Ciputra }\end{array}$ & $\begin{array}{c}A, B, C, D, \\
E, F, G, H, I \\
\text { J,K,L,M, } \\
N, O\end{array}$ & A-B-H-I-D-O & $\begin{array}{c}1- \\
(3,77 /(3,77+4,2+5,8)) \\
=72,6 \%\end{array}$ & efficient \\
\hline
\end{tabular}

\section{CONCLUSION}

Based on the research process that has been done, it can be concluded as follows:

1. The Optimum Travel Route EMBA * application can search on parse nodes with the EMBA * algorithm and can display routes from the original location to the destination on the map

2. Functions - functions that are in the Application Optimum Travel Route EMBA * can receive input and produce the appropriate output, evidenced by the conclusion on the Black Box Testing

3. After searching the route on 5 cases that exist in the table, the results obtained an efficient route compared with available routes with the percentage of efficiency of $77.5 \%, 53 \%, 53.8 \%, 73 \%$ and $72.6 \%$. The test results are classified with a good predicate because it finds an efficient solution in each case.

Below are some suggestions to be used as a reference in conducting further research in relation to Optimum EMBA * Applications, namely:

1. Application Optimum Travel Route EMBA * can be developed in mobile devices to support future technological developments

2. The process of parsing crossed-edge into a node can be developed so that it can be done automatically

\section{REFERENCES}

[1] D. Manongga, S. Papilaya, S. Pandie, F. T. Informasi, U. Kristen, S. Wacana, and J. D. Salatiga, "Sistem Informasi Geografis Untuk Perjalanan Wisata Di Kota Semarang," J. Inform., vol. 10, pp. 1-9, 2009.

[2] W. Wen, "A dynamic and automatic traffic light control expert system for solving the road congestion problem," vol. 34, pp. 2370-2381, 2008.

[3] Chrisman, "Exploring Geographic Information System." 1994.

[4] Bernhardsen, "Geographic Information Systems : An Introduction, 3rd Edition." 2002.

[5] C. L. Adrian, “A Collaborative GIS Solution for Public Transport,” vol. 13, no. 2, pp. 50-58, 2009. 
[6] D. W. Nugraha, "Perancangan Sistem Informasi Geografis Menggunakan Peta Digital," J. IIm. Forister, vol. 2, no. 1, 2012.

[7] T. Whangbo, “Efficient Modified Bidirectional A * Algorithm for Optimal Route-Finding," pp. 344-353, 2007. 